\title{
Lymphangiosarcoma arising in chronic congenital and idiopathic lymphoedema
}

\author{
D. H. MACKENZIE
}

From the Department of Morbid Anatomy, Westminster Medical School, London

SYNOPSIS A case of lymphangiosarcoma arising in chronic congenital and idiopathic lymphoedema is presented. The literature is reviewed and the diagnosis discussed.

Malignant tumours arising from the endothelium of blood vessels or lymphatics are rare. While haemangiosarcoma is accepted as a definite if uncommon entity, considerable controversy has surrounded the lymphangiosarcoma. Most of the literature has been concerned with tumours arising in oedematous arms following radical mastectomy (Stewart and Treves, 1948; Taswell, Soule, and Coventry, 1962). There has, however, been a number of reports of lymphangiosarcomas arising in limbs affected by congenital or chronic idiopathic lymphoedema in the absence of any other detectable malignant disease, and it is with this group only that the present communication is concerned.

Taswell et al (1962) listed four cases from the literature which they regarded as acceptable and added two more of their own. They also listed five probable ones. To these must be added the cases of Francis and Lindquist (1960), Scott, Nydick, and Conway (1960), Vandaele and van Craeynest (1963), Baes (1967), and McBride, Reeder, and Smith (1969).

Received for publication 26 November 1970.
These include cases diagnosed as lymphangio-을 sarcoma and angiosarcoma. There is a close relationship between the two, and Evans (1966) hases suggested that the term 'angiosarcoma' should beo used for all malignant tumours of endothelium. Details of the 16 cases are given in Table I.

Opinions regarding these cases have ranged from $\stackrel{乛}{-1}$ general acceptance to wholesale rejection by Salm $\vec{\varphi}$ (1963). In view of the wide differences of opinion thepresentation of a further case and a review of the other cases seemed justified.

\section{Case Report}

The patient, a man aged 64 , had suffered from an oedematous right leg since birth. Two months before admission the leg became heavier, more oedematous, painful, and ulcerated.

On examination the right leg was grossly oedematous, particularly below the knee, and there was? a large ulcer on the outer aspect of the calf (Fig. 1). There was some oedema of the thigh and the skin 3 .

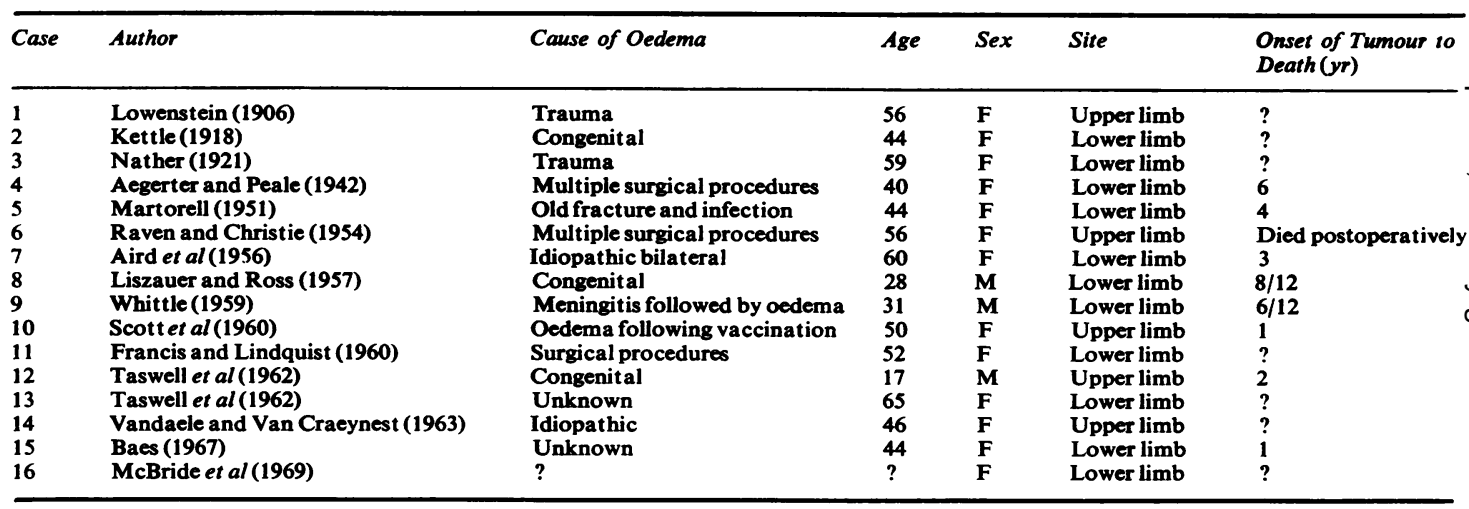

Table I Cases diagnosed as lymphangiosarcoma arising in chronic lymphoedema 


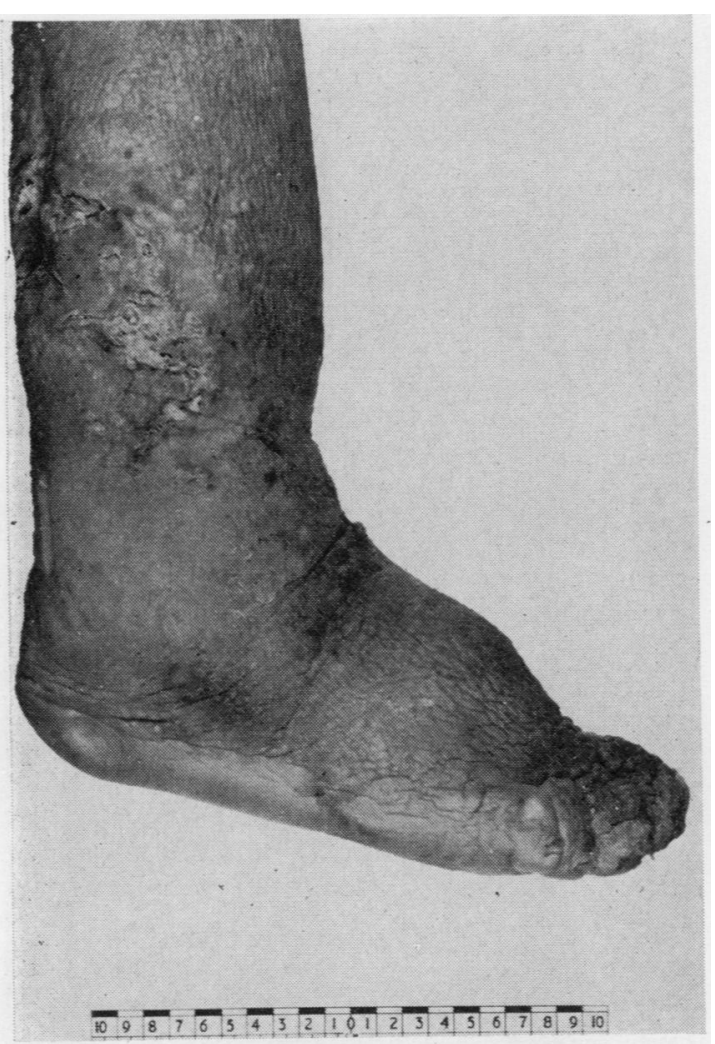

Fig. 1 Lower part of affected leg.

texture was abnormal up to the groin. In addition to the oedema and ulceration there were multiple nodular lesions of the skin and subcutaneous tissues from the foot to the knee. The patient was extensively investigated but no other lesion was demonstrable anywhere else in the body.

A hindquarter amputation was performed. Postoperatively the patient's general condition improved rapidly and on discharge he was reasonably active on crutches. He received postoperative supervoltage radiotherapy to the right inguinal and right paraortic areas. The patient is alive and well after two years.

\section{Pathology}

The operation specimen consisted of the right lower limb removed by hindquarter amputation. The appearances have been described above but, in addition, there were a number of enlarged external iliac lymph nodes.

\section{Microscopy}

Sections were stained with haematoxylin and eosin,

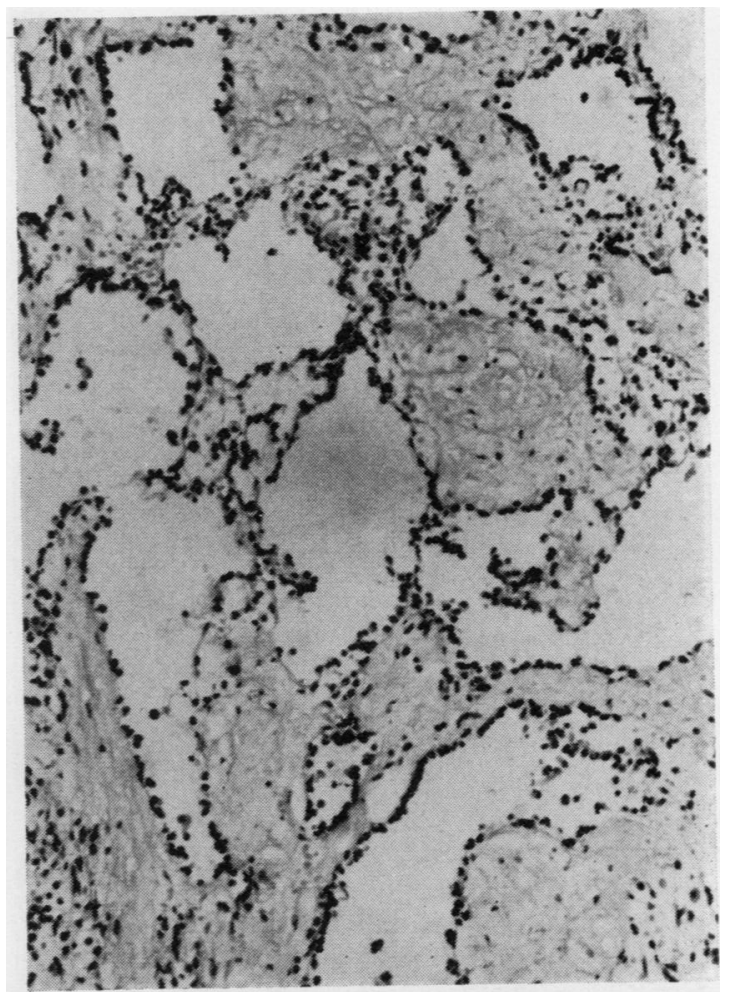

Fig. 2 Dilated lymphatic spaces lined by endothelium. Haematoxylin and eosin $\times 40$.

van Gieson, Gomori's reticulin stain, Sheridan's elastic stain, and by Sudan black for fat.

Numerous well defined channels lined by a single layer of endothelium were seen in many sections (Fig. 2). They were empty of blood. In many areas the endothelial cells were larger and more hyperchromatic and were clearly proliferating within the channels and within their reticulin sheaths (Figs. 3 and 4). In some fields the tumour assumed a more solid and clearly malignant appearance (Figs. 5 and 6). Some sections showed a fine honeycomb structure which appeared to be due to a sponge-work of channels of capillary size forming in the tumour tissue (Fig. 7). Fat stains were negative. Two external iliac lymph nodes attached to the specimen showed metastatic deposits (Figs. 8 and 9). The appearances were those of a lymphangiosarcoma arising in a chronically oedematous limb.

\section{Review of Previous Cases}

Inadequate documentation is the main problem facing a reviewer of the literature. It is often im- 


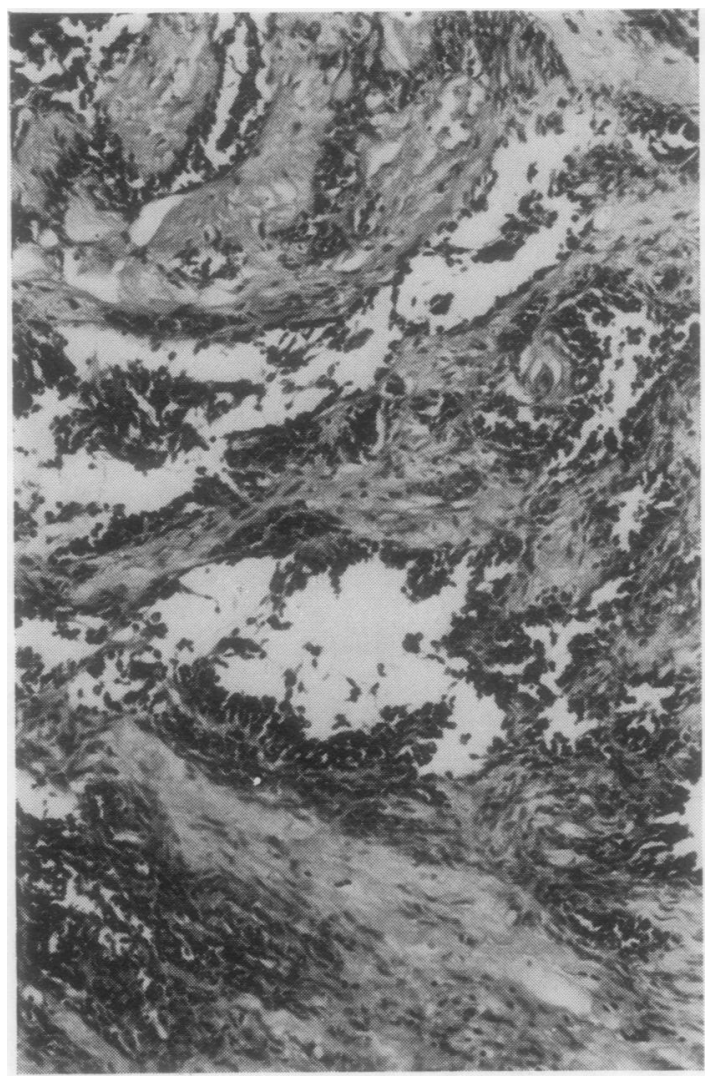

Fig. 3.

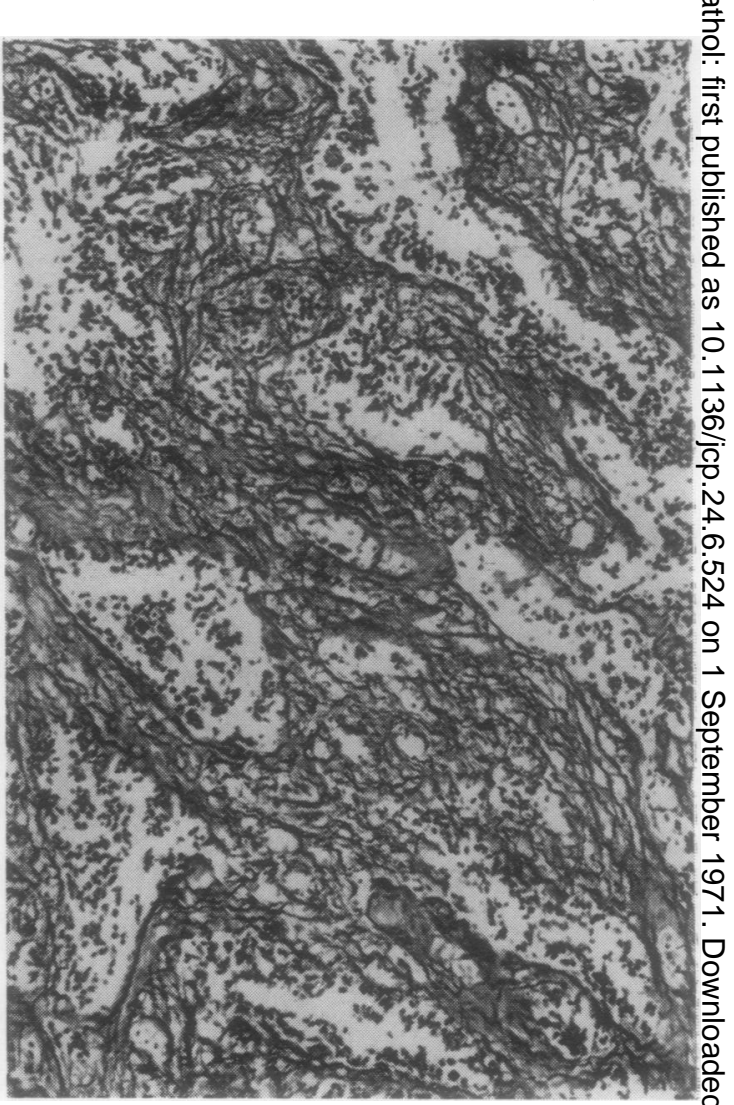

Fig. 4.

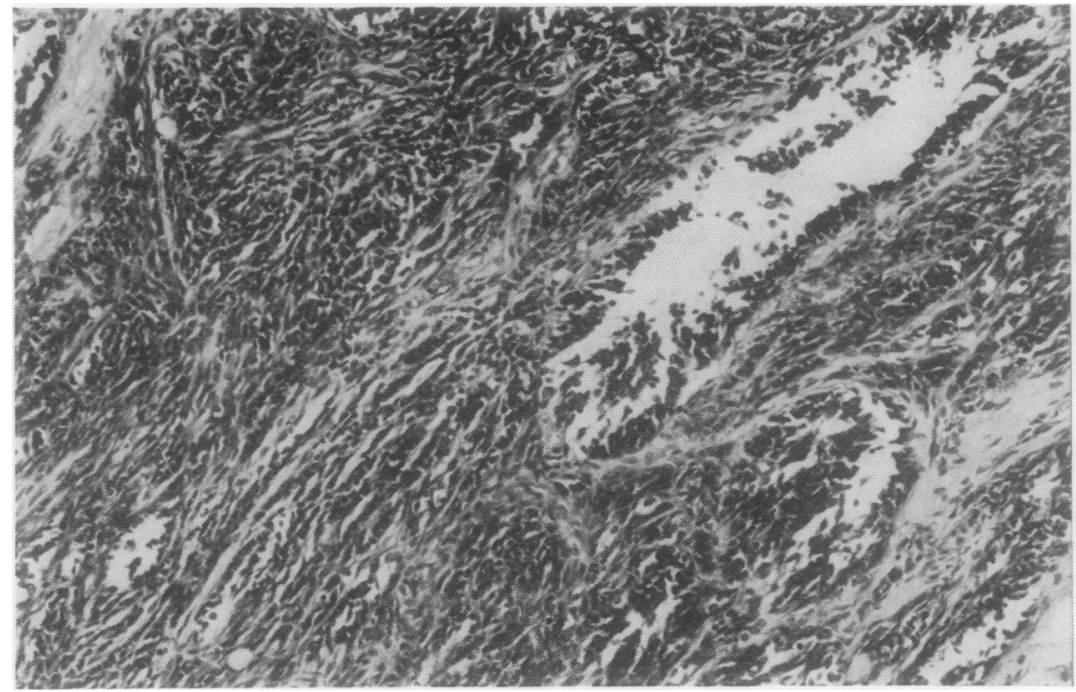

Fig. 5.
Fig. 3 Proliferating endothelial cells within lymphatic channels. Haematoxylin and eosin $\times 86$.

Fig. 4 Proliferating endothelial cells within reticulin sheaths. Gomori's reticulin stain $\times 80$.

Fig. $5 A$ malignant proliferation of closely packed endothelial cells. Haematoxylin and eosin $\times 86$. 


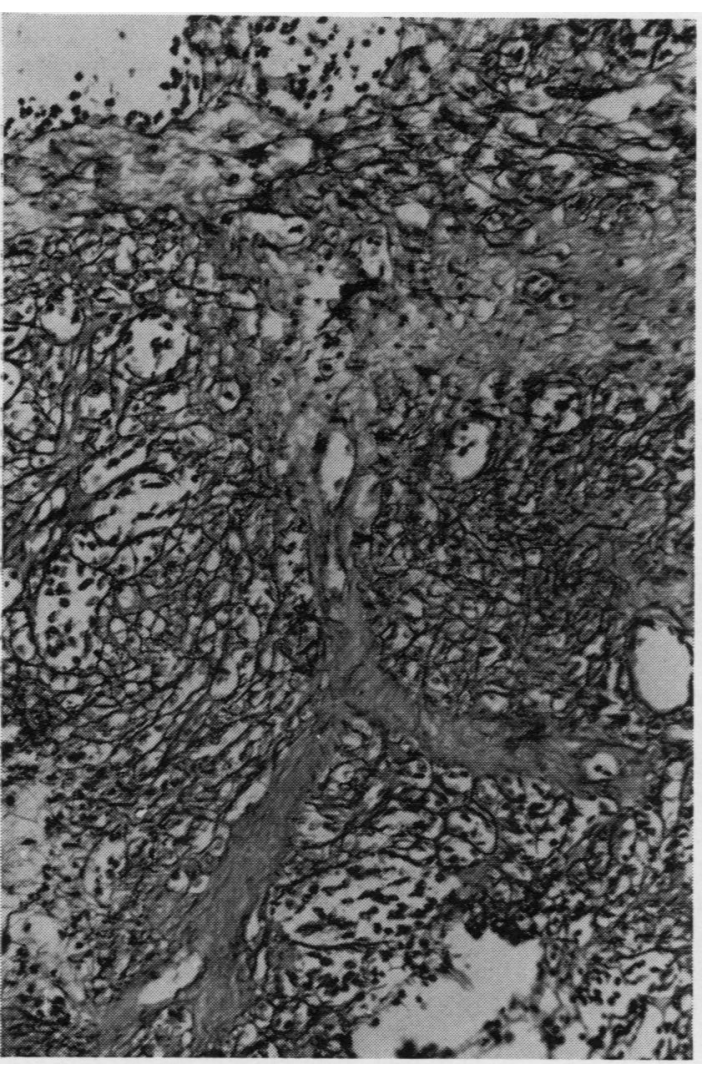

Fig. 6.

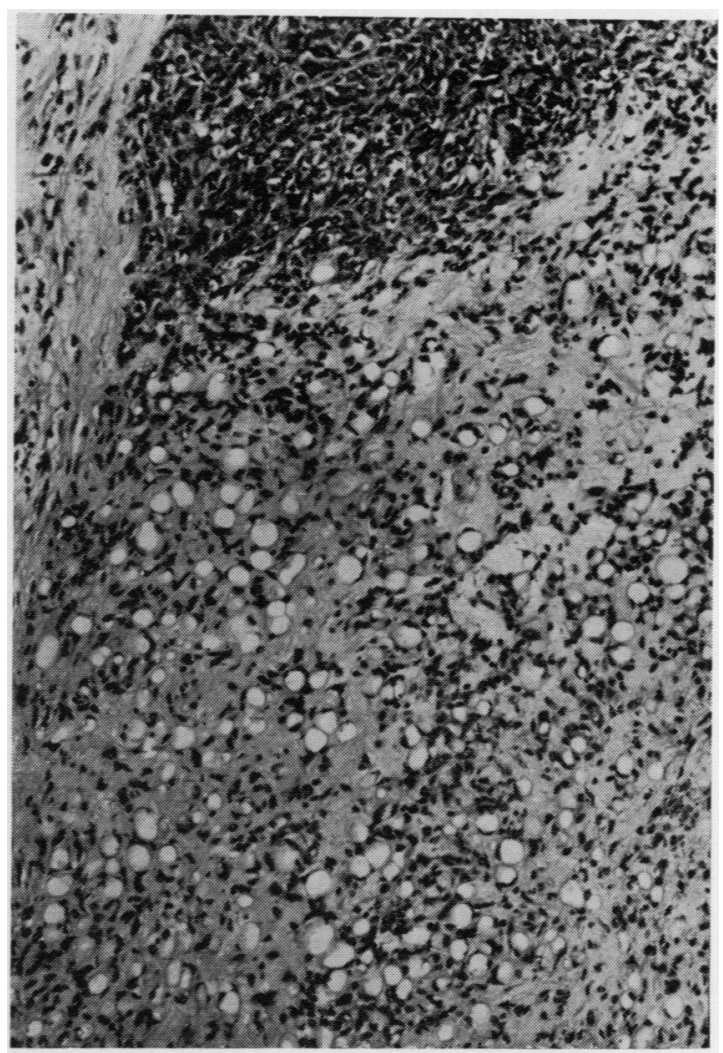

Fig. 7.

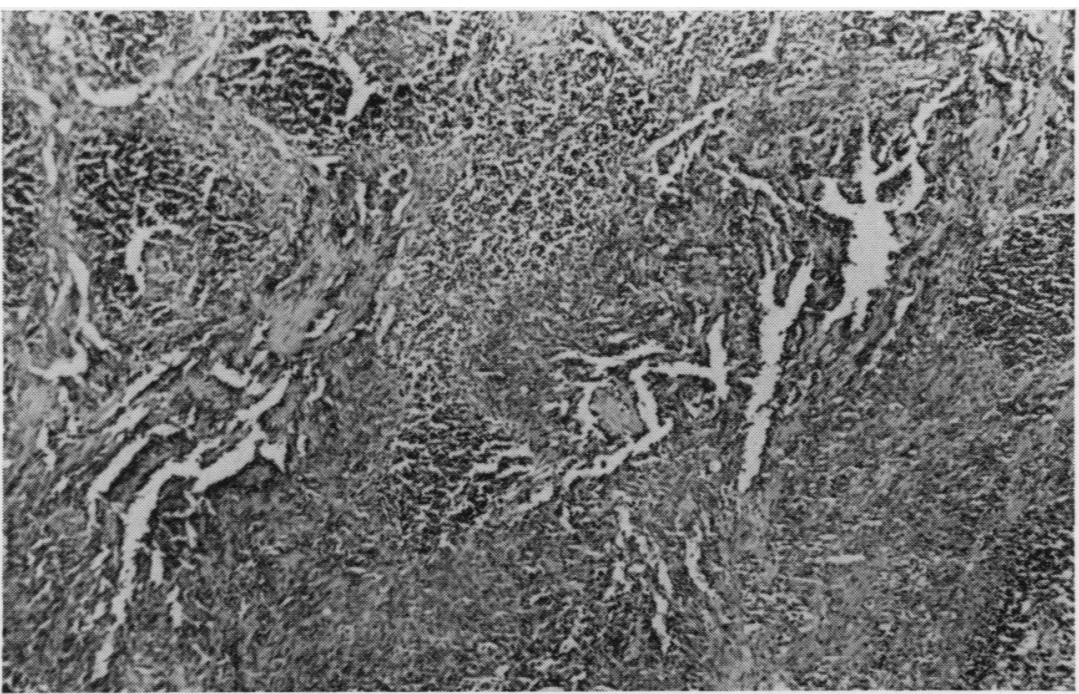

Fig. 8.
Fig. 6 A modified reticulin pattern in a cellular area of tumour. Gomori's reticulin stain $\times 80$.

Fig. 7 A spongework of capillary channels near a focus of solid tumour. Haematoxylin and eosin $\times 86$.

Fig. 8 Metastatic tumour in iliac lymph node. Haematoxylin and eosin $\times 56$. 


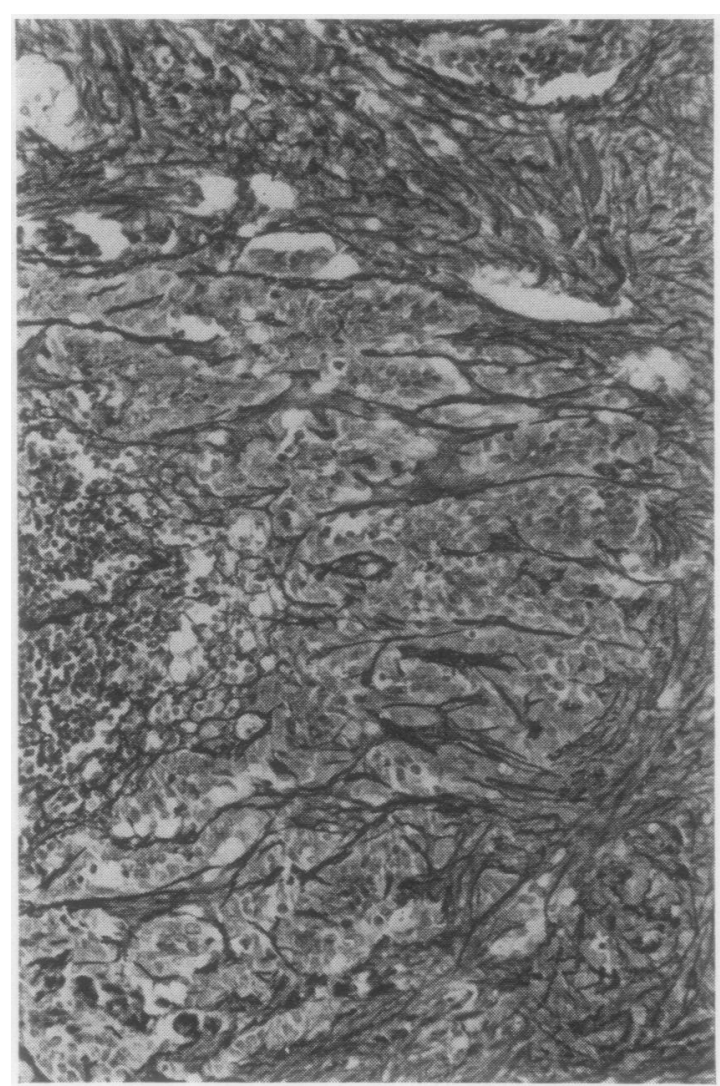

Fig. 9 Reticulin pattern in a solid area of metastatic tumour. Gomori's reticulin stain $\times 86$.

possible for him to examine the actual slides on which the diagnosis was based and he is, therefore, dependent entirely upon the photomicrographs in the relevant papers. It is clearly the duty of an author to prove his case beyond reasonable doubt, and this is particularly important with rare entities such as lymphangiosarcoma which may be very closely imitated by metastatic carcinoma. In fact Salm (1963) rejected not only the cases of Stewart and Treves (1948) but also those accepted by Taswell et al (1962) in the most recent available review of the subject in English. It is necessary to reconsider the cases listed in Table I.

The cases reported by Löwenstein (1906), Nather (1921), Martorell (1951), Liszauer and Ross (1957), and Vandaele and van Craeynest (1963) are excluded either because the reports are devoid of illustrations or because the quality of the photomicrographs is too poor to substantiate the diagnosis or to exclude the possibility of carcinoma. The cases described by Francis and Lindquist (1960) and by McBride et al (1969) were known to have had other primary tumours and the photomicro-s? graphs do not exclude the possibility of metastases. The case of Aegerter and Peale (1942) appears too have been an example of Kaposi's sarcoma while $\frac{\bar{s}}{-}$ that of Raven and Christie (1954) concerned malig- $-\mathbb{Q}$ nant change in a benign angioma with no mentiong of oedema at the initial presentation. These are, therefore, excluded. In the case of Scott et al (1960) the tumours were variously diagnosed as papilloma, $\overrightarrow{\vec{\omega}}$ sclerosing angioma, lymphangiosarcoma, and, one two occasions, as synovial sarcoma. The photo $=\frac{8}{8}$ micrographs are not conclusive and their Fig. 6 i would certainly do for a monophasic area in $\mathrm{a}_{i}^{+}$ synovial sarcoma. This case must also be excluded. if

The remaining six cases are, in my opinion, acceptable. Through the courtesy of Professor Harrison? and Professor Weinbren I have been able to examinethe postmortem sections of the case reported byc Aird, Weinbren, and Walter (1956) and these? together with the photomicrographs shown in the paper, appear to confirm the diagnosis. Througho the courtesy of Dr A. Stansfeld I have been able to examine the initial section of the case of Whittlece (1959). This was undoubtedly a vasoformative tumour and in no way suggested a carcinoma of the skin. The evidence in the other four cases, while not entirely conclusive, seems to justify their inclusion The acceptable cases are shown in Table II.

\begin{tabular}{|c|c|}
\hline Case No. & Author \\
\hline $\begin{array}{l}1 \\
2 \\
3 \\
4 \\
5 \\
6\end{array}$ & $\begin{array}{l}\text { Kettle (1908) } \\
\text { Aird et al (1956) } \\
\text { Whit tle (1959) } \\
\text { Taswell et al (1962), case } 12 \\
\text { Taswell et al (1962), case } 13 \\
\text { Baes (1967) }\end{array}$ \\
\hline
\end{tabular}

Table II Acceptable cases of lymphangiosarcoma and angiosarcoma arising in chronic lymphoedema

\section{Discussion}

In reducing the number of acceptable cases from 16 to six it must be admitted that injustice may have been done to a number of authors. A study of thesen cases shows a remarkable consistency in the clinican picture and in the naked-eye appearances of theo affected limbs. This suggests, but does not prove the accuracy of the diagnosis. Authors have an obligation to provide conclusive photomicrographse? in support of their suggested diagnosis. One of the most unfortunate features of the photomicrographso shown in these cases has been the lack of a reticulin $\mathbb{\mathrm { D }}_{\mathrm{C}}$ stain to illustrate the vasoformative nature of the neoplasm and to show that the proliferating tumour 
cells do indeed lie within the reticulin sheaths. In this connexion it must be stressed that in highly cellular endothelial neoplasms the diagnostic reticulin pattern may be modified or lost and such reticulin variations are shown in Figures 4, 6, and 9. In the majority of cases, however, the examination of multiple sections will provide the vital information. Reticulin stains must be carried out in all suspected cases and these are particularly important if the patient has previously suffered from a primary neoplasm elsewhere. Willis (1967) has rightly stressed the importance of applying the very strictest criteria before the diagnosis of angiosarcoma or lymphangiosarcoma can be accepted.

I am indebted to Mr E. Stanley Lee for permission to publish this case. I wish to thank Professor R. A. Willis for reviewing the sections and confirming the diagnosis. My thanks are also due to the Department of Medical Photography, Westminster Hospital.

\section{References}

Aergerter, E. E., and Peale, A. R. (1942). Kaposi's sarcoma. Arch. Path., 34, 413-422.

Aird, I., Weinbren, K., and Walter, L. (1956). Angiosarcoma in a limb the seat of spontaneous lymphoedema. Brit. J. Cancer, 10, 424-430.
Baes, H. (1967). Angiosarcoma in a chronic lymphoedematous leg. Dermatologica (Basel), 132, 331-336.

Evans, R. W. (1966). Histological Appearances of Tumours, p. 107. Livingstone, Edinburgh and London.

Francis, K. C., and Lindquist, H. D. (1960). Lymphangiosarcoma of the lower extremity involved with chronic lymphedema. Amer. J. Surg., 100,617-619.

Ket tle, E. H. (1918). Tumours arising from endothelium. Proc. roy. Soc. Med., 11, 19-34.

Liszauer, S., and Ross, R. C. (1957). Lymphangiosarcoma in lymphoedema. Canad. med. Ass. J., 76, 475-477.

Löwenstein, S. (1906). Der ätiologische Zusammenhang zwischen akutem einmalgem Trauma und Sarkom: Ein beitrag zur Aetiologie dermalignen Tumoren. Bruns' Beitr. Klin. Chir., 48, 780-824.

Martorell, F. (1951). Tumorigenic lymphedema. Angiology, 2, 386-392. McBride, C. M., Reeder, J. W., and Smith, J. L. (1969). Angiosarcoma in the lymphedematous limb. Sth. med. J., 62, 378-380.

Nather, K. (1921). Ueber ein malignes Lymphangioendotheliom der Haut des Fusses. Virchows Arch. path. Anat., 231, 540-556.

Raven, R. W., and Christie, A. C. (1954). Haemangiosarcoma: a case with lymphatic and haematogenous metastases. Brit. J. Surg. 41, 483-489.

Salm, R. (1963). The nature of the so-called postmastectomy lymphangiosarcoma. J. Path. Bact., 85, 445-456.

Scott, R. B., Nydick, I, and Conway, H. (1960). Lymphangiosarcoma arising in lymphedema. Amer.J. Med., 28, 1008-1012.

Stewart, F. W., and Treves, N. (1948). Lymphangiosarcoma in postmastectomy lymphedema. A report of 6 cases in elephantiasis chirurgica. Cancer (Philad.), 1, 64-81.

Taswell, H. F., Soule, E. H., and Coventry, M. B. (1962). Lymphangiosarcoma arising in chronic lymphedematous extremities. J. Bone Jt Surg., 44a, 277-294.

Vandaele, R., and van Craeynest, W. (1963). Lymphangiosarcome sur lymphoedéme primitif due bras. Bull. Soc. franç. Derm. Syph., 70,722-725.

Whittle, R. J. M. (1959). An angiosarcoma associated with an oedematous limb. A case report.J. Fac. Radiol. (Lond.), 10, 111-112.

Willis, R. A. (1967). Pathology of Tumours, p. 244. Butterworths, London. 